\title{
THE ROLE OF ATTACHMENT STYLE ON FRIENDSHIPS AND SIBLING RELATIONSHIPS OF ADOLESCENTS
}

\author{
Kirti Dixit
}

\author{
Banaras Hindu University \\ kirtidixit7565@gmail.com
}

DOI: 10.26821/IJSRC.9.4.2021.9409

\begin{abstract}
The aim of the present study is to investigate the role of attachment style on friendships and sibling relationships. Adolescence is a stage of physical as well as psychological changes in children. Attachment style is seen to be a significant factor in adult relationships, but little is known about their interconnectedness and specific features, which is the prime focus of this study.
\end{abstract}

Keywords: attachment style, relationships, secure, positive, negative, qualities

\subsection{INTRODUCTION}

\subsubsection{ATTACHMENT STYLE}

Bowlby (1969) defines attachment as an affective relationship characterized by a tendency to demand and retain closeness with certain persons, especially when an individual is under stress. Attachment is formed in infancy between a child and a person or persons taking care of the child, which, in most cases, is the mother. Depending on the mother's behaviour towards the new born, the quality of their relationship, the mother's noticing of the child's signals and their correct interpretation, adequate responding, care and gentleness, three types of the child's attachment to the mother are formed: secure attachment, avoidant attachment, or anxious-ambivalent attachment (Ainsworth, Blehar, Waters, \& Wall, 1978). If the mother notices the child's signals, interprets them correctly and responds adequately, with care and gentleness, her child will develop the secure attachment style. On the other hand, if the mother is cold and does not respond to the child's needs, the child will develop the avoidant attachment style. Finally, the mother who sometimes responds to her child's needs with warmth and care, and sometimes coldly ignores them, will probably have a child with the anxious ambivalent attachment style. Although the attachment theory emerged as an explanation of the emotional relationship between a child and a caregiver, Bowlby (1969) thinks that the same attachment style system exists and functions throughout the individual's lifetime. Attached behaviour becomes organized within one's self as an internal working model that defines emotional relationships during one's life. Namely, a child develops an internal working model based on the mother's adequate responding to the child's needs. These internal working models shape child's expectations of other people, as well as of self. Knowing how often our expectations define our perception, cognition and behaviour (e.g. selffulfilling prophecy), it is not surprising that internal working models developed in childhood can be resistant to change and can have long-term continuity in shaping our world. Based on the attachment theory, it can be concluded that the type of attachment once adopted in childhood works and structures the quality of relationships in adolescence and adult life. Whereas in childhood parents are usually the main objects of attachment, during adolescence the hierarchy of the objects of attachment changes - young people become more oriented towards their peers. Although parents do not cease to be objects of attachment at that age nor later in life, it is believed that they are slowly becoming "objects of attachment in reserve". Any relationship in the adult phase is a potential source of attachment. 
Volume 9 Issue 4 April 2021

\subsubsection{THEORITICAL FRAMEWORK}

- Mary Ainsworth conducted an experimental procedure to observe the attachment forms between mothers and infants. The procedure is referred as strange situation by observing eight episodes of parent child interaction. She concluded three attachment styles: secure, insecure avoidant and insecure ambivalent.

- BOWLBY'S ATTACHMENT THEORY $(1969 / 1982,1979)$ is a prominent theory to conceptualise the parent-child relationship (Mikulincer, shaver and Perger, 2003). He applied the idea of infant-caregiver bond and emphasized that the quality of attachment with the caregiver determine the child's feelings of security and trustworthy relationships in his future life. With the advent of time and experiences with the caregiver's children develop an affectionate tie which serves as an image of internal working model. This model shapes their personality and a guiding principle for their relationships (Bretherton and Munholland, 1990). A secure parental tie is necessary for successful development of late adolescence which is developed when the infant explores the world using parents as a "secure base", by Bowlby (1969).

\subsubsection{RELATIONSHIPS}

"Close relationships are a cornerstone of successful adaptation and a reliable marker of individual adjustment. Supportive relationships have been linked to adolescent social and academic competence, but models of relationship influence remain speculative" (Collins \& Steinberg, 2006).A lot of studies have examined both positive and negative aspects of adolescence parents and friendships but the individual differences are not well understood. The present study in adolescence and their relationships with friends' siblings and attachment with their parents. The focus on perceptions of relationship quality because subjective use a better product as a wellbeing then objective indices of behaviour in relationships (Gottlieb,1985). The positive qualities include companionship, disclosure, emotional support, approval and satisfaction and negative qualities include conflict, criticism, pressure, exclusion and dominance. These positive and negative qualities are independent dominance not opposite ends of a continuum. When in a relationship, adolescents considered these positive and negative attributes to be orthogonal (Barrera et.al., 1993). This positive and negative feature of parent child and friends'relationships independently predict external problems internal problems and academic achievement of adolescents (Adams and Laursen, 2007). However, very less is known about individual differences in patterns of positive and negative features and that influence on adolescence attachment style, which is further the prime focus of this study.

\subsubsection{THEORITICAL BACKGROUND}

- Freud's psychosexual stages of latency and genital corresponds to adolescents. The former is where libido is dormant. In this stage, sexual impulses are lost and sexual energy is sublimated towards school work and friendships. The latter refers the time of sexual orientation, the successful completion infers formation of a stable romantic relationship.

According to Erikson, adolescents are categorised under the stage of identity vs role confusion. In this stage, the adolescents explore possibilities and lead to formation of their own identity. The successful completion of this stage leads to fidelity (ability of commitment to an individual by acceptance) whereas failure leads to role confusion about one's own self in society. The important event here is formation of relationships.

\subsubsection{FRIENDSHIPS}

Friendship can be defined as a dyadic relationship which is often horizontal because the sense of equality is at their core. A parent child or a sibling relationship is more vertical in nature because the partners different age and developmental stages. Sullivan noted that the basic starting point of friendship is reciprocity. If peers can imitate their acts, their friendship is more open to positive as well as negative features in their relationship these are the basic specific beginning of their friendship. 
Volume 9 Issue 4 April 2021

All the peers practice symmetrical reciprocity friends agree to a consensual agreement to treat each other as they want to be treated.

Formation of close mutual friendships and important developmental task during adolescence stage (Berndt,1982). The goal of the current research was to examine the role of attachment style to the quality of friendship in adolescence attachment theory of a framework which also exam examines differences in friendship quality full stop a link between attachment and friendship is explain why working models are the beliefs of self and others (Bowlby,1973). They are thought to develop child experiences in relationships with the attachment figures that is their parents working models also provide the child with the expectation of what a relationship should like and how it should affect their behaviour in other close relationships. Adolescence who report more positive experiences with friends also report higher self-esteem and lower levels of depression and anxiety (Townsend et. al., 1988), suggesting that friendship enhance adjustments.

An explanation for the link between friendships and attachment style of the child the child might imitate a particular interaction style with others based on their interactions with their primary caregivers (Youngblade and Belsky, 1992). The next explanation is that emotional regulation actas a mediator between friendship and attachment style (Tomich, 2000). For example, a child might start to distance himself or herself from the caregiver when they are upset and subsequently seek less intimacy and other positive features from the friends as well. Consistent with the hypothesis prior studies have shown that attachment and friendship quality are related during early and middle childhood (Freitag, Belsky, Grossmann, Grossmann, \& ScheuererEnglisch, 1996; Kerns, 1994; Kerns, Klepac, \& Cole, 1996; Lieberman, Doyle, \& Markiewicz, 1999; Park \& Waters, 1989; Schneider, Atkinson, \& Tardif, 2001; Shulman, Elicker, \& Sroufe, 1994; Youngblade, Park, \& Belsky, 1993).

\subsubsection{SIBLING RELATIONSHIPS}

Adolescence undergo changes in their family relationships along with other psychological and physical changes in general these changes a decrease in relationships with their families and increase in their relationships with their friends
(Degirmencioglu, Urber, Tolson, \&Richard, 1998; Savin-Williams \& Berndt, 1990). Children progress through the through their adolescence high conflict level decrease centre machine sibling relationship increases or stays stable in early and late adolescence (Burhmester, 1992; Updegraff, McHale, \& Crouter, 2002). Many studies focus on family relationships but very few of them analyse sibling relationships. During childhood a child perceives the siblings as playmates but during adolescence this relationship becomes a centre for providing support and intimacy required during socio economic and cognitive changes in their lives (Yenes, Olabarrieta, Arranz, \& Artamendi, 2000). Sibling relationships during adolescence and never exclusively conflict, they also contain elements of inter sibling help and social support. Researchers suggest that quality of sibling relationship is linked to their peer relationships and adjustments (Stocker, Burwell and Briggs, 2002).

Thus, the question that will be addressed in the study is "Does friendships and sibling relationships differ according to the attachment style of adolescents?"

\subsection{REVIEW OF LITERATURE}

Dam D. (2018) conducted a research on "Childhood maltreatment (ChM), adult attachment and psychotic symptomatology: a study in patients, siblings and controls". Results suggest that in siblings, the relationship between $\mathrm{ChM}$ and psychosis seems to be mediated by adult attachment style.

Heinze J. et. al. (2018) conducted a research on "Friendship Attachment Style Moderates the Effect of Adolescent Exposure to Violence on Emerging Adult Depression and Anxiety Trajectories". Results suggest securely attached adolescents reported faster decreases in mental health symptoms as a function of violence relative to their insecurely attached peers as they transitioned into adulthood.

Sommantico S. et. al. (2018) conducted a research on 'Predicting Young Adults' Romantic Relationship Quality: Sibling Ties and Adult Attachment Styles". Findings only partly supported the hypotheses, indicating that more positive attitudes toward sibling relationships and lower use of behaviours associated with avoidant attachment 
Volume 9 Issue 4 April 2021

style influenced and predicted higher romantic relationship quality.

McCarthy (2011) conducted a research on "Attachment style and adult love relationships and friendships: A study of a group of women at risk of experiencing relationship difficulties". Women with a secure attachment style had more positive ratings in the domain of adult love relationships than women with insecure attachment style (avoidant and ambivalent) and difficulties in adult love relationships were found to be particularly related to an avoidant attachment style. Insecure attachment style was also related to having cohabited with a deviant partner.

Akhtar Z. (2010) conducted a research on "The Effect of Parenting Style of Parents on the Attachment Styles of Undergraduate Students". Results showed there was significant relationship between authoritarian parenting style of parents and anxious attachment style of students. There was significant relationship between permissive parenting style with avoidant and anxious attachment style respectively.

Myers S. and Goodboy A. (2010) conducted a research on "Relational Maintenance Behaviours and Communication Channel Use among Adult Siblings". These findings suggest that when it comes to maintaining their sibling relationships, adults may consider the extent to which they experience emotional interdependence and psychological closeness with each other.

Bimpus A. and Rollin E. (2009) conducted a research on "Attachment style differences in relational maintenance and conflict behaviours: Friends' perceptions". Findings revealed that friends reported greater relationship satisfaction, greater use of prosocial maintenance strategies, and more integrating and compromising conflict behaviour for securely attached individuals as compared to preoccupied, dismissive, and fearful.

Boute V. et. al. (2009) conducted a research on "Exploring similarities and differences between online and offline friendships: The role of attachment style". The results suggest that the extent to which individuals sought out online friends did not differ as a function of attachment style.
Fraley R. and Davis K. (2005) conducted a research on "Attachment formation and transfer in young adults' close friendships and romantic relationships". The results suggest that factors that generally promote the development of attachment formation in infancy (such as care giving, trust, and intimate contact) were found to be positively associated with the development of attachment in adult relationships.

Grabbil C. and Kerns K. (2005) conducted a research on "Attachment style and intimacy in friendship" Two studies with college students tested the hypothesis that a secure attachment style enhances intimacy in friendship. Three intimacy characteristics were studied: self- disclosure; responsiveness to a partner's disclosure; and feeling understood, validated, and cared for by a partner during conversations. Both studies found gender differences in intimacy characteristics.

Saferstein et. al. (2005) conducted a research on "attachment as a predictor of friendship qualities in college youth". Results indicated that securely attached individuals showed higher levels of transcending problems in their friendships and lower levels of conflict, while avoidant individuals showed higher levels of conflict and lower levels of companionship. Interactions between attachment style, sex of the participant, and the sex of the friend (same/opposite sex) suggested the combined impact of these variables on specific friendship qualities.

Weimer B. et. al. (2004) conducted a research on "Adolescents' interactions with a best friend: Associations with attachment style". The findings suggest that security of attachment, rather than type of insecurity, is most related to intimacy in friendship.

Ciechanowski P. et. al (2003) conducted a research on "The relationship of attachment style to depression, catastrophizing and health care utilization in patients with chronic pain". The findings suggest that attachment style may be a useful construct for examining factors affecting adjustment and treatment response of patients with chronic pain. 
Mikulincer M. and Selinger M. (2001) conducted a research on "The Interplay between Attachment and Affiliation Systems in Adolescents' Same-Sex Friendships: The Role of Attachment Style" Findings indicated that secure adolescents attached high importance to both attachment and affiliation goals in friendship, anxious-ambivalent adolescents overemphasized attachment goals, and avoidant adolescents gave low importance to the two types of goals.

Milevsky A. et. al. (2011) conducted a research on "Effects of parenting style and involvement in sibling conflict on adolescent sibling relationships". The results highlight indirect and direct relationships between parental behaviour and sibling relationship quality

Neil J. and Horbury D. (2001) conducted a research on "The Effects of Parenting Styles and Childhood Attachment Patterns on Intimate Relationships". Results show that although $92 \%$ of the students with authoritative parenting styles are also securely attached, that only attachment styles predict intimacy patterns. Those students who were securely attached to their parents scored significantly higher on tests of personal intimacy and belief in other's abilities to be intimate as opposed to those students with authoritarian or permissive parents. Results are discussed in the context that attachment patterns form an early working model while parenting styles are more prevalent when the child is older and may affect other variables.

\subsection{RATIONALE}

The purpose of this research is to explore the role of attachment style in the interpersonal relationships of adolescents, focussing on friendships and sibling relationships. The current review of literature suggests a significant relationship between attachment style and friendships and sibling relationships. Little is however known about their interconnectedness specially sibling relationships with their respective positive and negative qualities. Thus, the study aims at examining the relationship between attachment style with friendships and sibling relationships.

\subsection{AIM:}

To study the role of attachment style in friendships and sibling relationships of adolescents.

\subsection{OBJECTIVE:}

To investigate the differences in friendships and sibling relationships of secure and non-secure individuals.

\subsection{HYPOTHESIS:}

H1: There are significant differences in positive features of friendships in secure and non-secure individuals.

$\mathrm{H} 2$ : There are significant differences in negative features of friendships in secure and non-secure individuals.

H3: There are significant differences in positive features of sibling relationship in secure and non-secure individuals.

H4: There are significant differences in positive features of sibling relationships in secure and non-secure individuals.

\subsection{RESEARCH DESIGN:}

Quasi experimental research design was used in the study. It was used to study the role of attachment style in friendships and sibling relationships. 100 participants, including 50 males and 50 females were included in the study within the age range of 15-19 years. SPSS was used to compute the results, further t-test was used to measure the role of attachment style in friendships and sibling relationships.

\subsection{VARIABLES:}

INDEPENDENT VARIABLE: Qualities of friendship and sibling relationship

Friendship and sibling relationships are further measured in terms of positive qualities (closeness) and negative qualities (discord). Positive qualities include companionship, disclosure, emotional support, approval and satisfaction whereas negative qualities include conflict, criticism, pressure, exclusion and dominance.

DEPENDENT VARIABLE: Attachment style

Attachment style is studied in terms of secure and non-secure attachment style. Non-secure 
Volume 9 Issue 4 April 2021

attachment style includes: preoccupied, fearful avoidant and dismissing avoidant.

Figure 1: Table for variables: independent and dependent

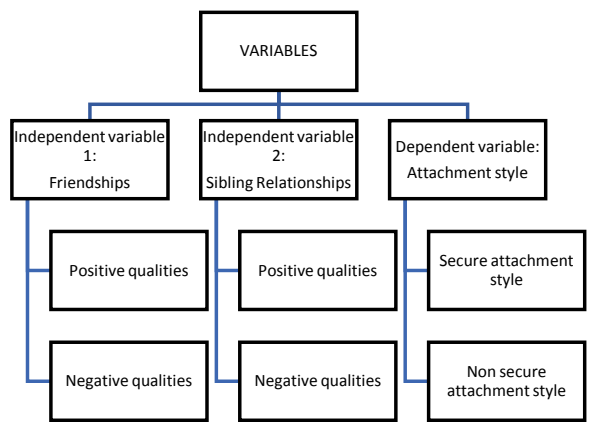

\subsection{SAMPLE AND SELECTION}

The study was done on 100 participants of the age 15-19, where 50 were males and 50 were females. Purposive sampling was used for the simplification of conduction of study.

\subsection{DESCRIPTION OF TOOLS}

Two instruments were used for data collection process. The questionnaire consisted of demographic information,Experience in Closed Relationships-Revised and Network

Relationships Inventory- Relationship Qualities Version:

Demographic Information: Demographic section assessed basic information of participants including name, age, gender, religion, educational qualification, number of siblings, type of family, socio-economic status and the type of employment of their father and mother.

Experience in Closed Relationships-Revised: ECR$\mathrm{R}$ developed by Fraley et al. (2000) is used to assess the parental attachment style of adolescents.

The validity of the test is 0.82 . The reliability of the test for:

- Cronbach alpha: 0.81 by Fraley et al. (2000)

- Test retest reliability: 0.82 by Farey et al. (2000)

The ECR-R questionnaire involves 36 items using a 7-pointLikert scale to indicate how strongly the participants agree or disagree to the statements given. The questionnaire consists of two subscalesanxiety and avoidance dimension. Four linear discriminant functions as outlined in Brennan et al. are used to calculate four attachment style categories:

- $\quad$ Secure (low avoidance and anxiety)

- Dismissive (low anxiety and high avoidance),

- Fearful-avoidant (high anxiety and avoidance)

- Preoccupied (low avoidance and high anxiety)

Figure 1: Interpretation of attachment styles

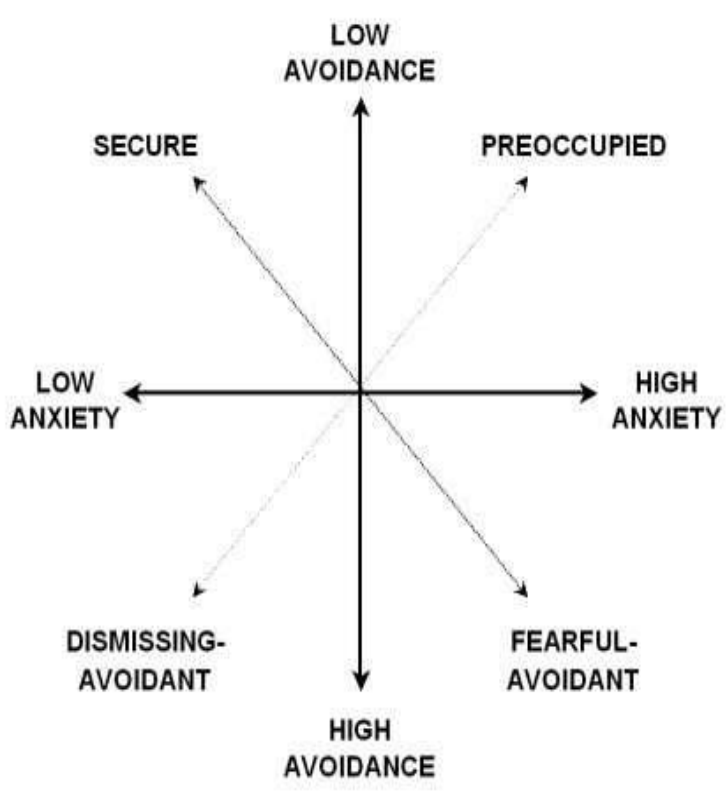

Network of Relationships Inventory- Relationship Qualities Version: The inventory developed by Wyndol Furman and Duane Buhrmester was used to assess the relationships of adolescents with their friends and sibling. The inventory consists of 30 questions to assess ten relationship qualities (Furman and Burhmester, 1985). Analysis was done using the scores of closeness and discord.

The criterion validity was assessed by peers and their scores of NRI. The correlations ranged from 0.34 to 0.63 (Touliatos, Perlmutte, Straus \& 
Volume 9 Issue 4 April 2021

Holden, 2001). Reliability is computed as: friendship: 0.737 and sibling relationship: 0.751

\subsection{PROCEDURE}

To investigate the effect of attachment style and relationships of adolescents with friends and sibling, the research was initiated. The relationship between parental attachment style and relationships of adolescents was also taken into account. Literature review was collected and the various researches were studied. The tools for data collection for all the variables were gathered. Next, the hypotheses were formulated and the expected outcomes were identified. The students from different schools were identified and approached for data collection. The purpose of the present study was explained in brief to all the participants and their doubts related to the questionnaire were cleared. The participants were both males and females; they were taken in equal proportions. Upon giving the instructions to the participants, data was collected. It was collected via offline hardcopy of the questionnaire.

Once the desired responses were gathered, participants were thanked for their valuable responses and time. The scores were compiled in excel sheets for each variable and each participant. For the analysis of raw scores, the help of SPSS was taken. The mean, standard deviation for the parental attachment style and relationships of adolescents were calculated. T-test technique was also employed using SPSS to understand the relationship among the variables. Once the results were tabulated, the interpretation and analysis of the results was done. Further, the limitations of the study, implication of the study and recommendation for future research in the field were written.

\subsection{STATISTICAL ANALYSIS}

- The sample mean and standard deviation is calculated.

- T-test, a statistical technique is used to investigate significant differences between parental attachment style and relationships was used in the study.

\section{RESULTS}

Table 1: Descriptive Statistics

$\begin{array}{llll}\text { Attachment N } & \text { Mean SD } \\ \text { Style } & & & \\ \end{array}$

\begin{tabular}{|c|c|c|c|c|}
\hline $\begin{array}{l}\text { Positive } \\
\text { qualities } \\
\text { of friends }\end{array}$ & SECURE & 83 & 15.34 & 6.730 \\
\hline & $\begin{array}{l}\text { NON- } \\
\text { SECURE }\end{array}$ & 13 & 18.23 & 4.969 \\
\hline \multirow[t]{2}{*}{$\begin{array}{l}\text { Negative } \\
\text { qualities } \\
\text { of friends }\end{array}$} & SECURE & 83 & 9.64 & 5.006 \\
\hline & $\begin{array}{l}\text { NON- } \\
\text { SECURE }\end{array}$ & 13 & 10.23 & 3.345 \\
\hline \multirow[t]{2}{*}{$\begin{array}{l}\text { Positive } \\
\text { qualities } \\
\text { of } \\
\text { siblings }\end{array}$} & SECURE & 84 & 13.57 & 6.864 \\
\hline & $\begin{array}{l}\text { NON- } \\
\text { SECURE }\end{array}$ & 13 & 8.92 & 6.344 \\
\hline $\begin{array}{l}\text { Negative } \\
\text { qualities } \\
\text { of } \\
\text { siblings }\end{array}$ & SECURE & 84 & 10.67 & 5.304 \\
\hline & $\begin{array}{l}\text { NON- } \\
\text { SECURE }\end{array}$ & 13 & 11.08 & 7.041 \\
\hline
\end{tabular}

Graph 1: Mean scores of Qualities of Relationships

Graph 1: Mean scores of

Qualities of Relationships

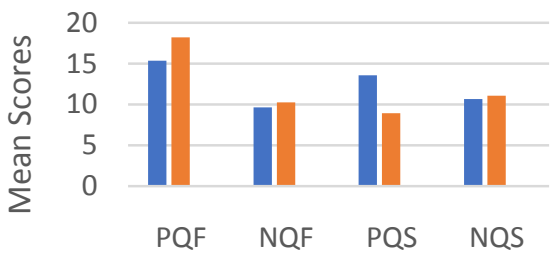

Qualities of Relationships

- SECURE $\square$ NON SECURE $\square$ Column1

The above graph depicts the mean scores of positive and negative qualities in friendships and sibling relationships.

Table 2: Independent Samples Test

\begin{tabular}{|c|c|c|c|c|c|}
\hline & $\mathbf{F}$ & Sig. & $\mathbf{t}$ & df & $\mathbf{p}$ \\
\hline $\begin{array}{l}\text { Positive } \\
\text { qualities } \\
\text { of } \\
\text { friends }\end{array}$ & .512 & .476 & -1.485 & 94 & .141 \\
\hline $\begin{array}{l}\text { Negative } \\
\text { qualities } \\
\text { of } \\
\text { friends }\end{array}$ & 3.065 & .083 & -.411 & 94 & .682 \\
\hline
\end{tabular}


Volume 9 Issue 4 April 2021

\begin{tabular}{llllll}
\hline $\begin{array}{l}\text { Positive } \\
\text { qualities } \\
\text { of } \\
\text { siblings }\end{array}$ & .199 & .657 & 2.293 & 95 & .024 \\
\hline $\begin{array}{l}\text { Negative } \\
\text { qualities } \\
\text { of } \\
\text { siblings }\end{array}$ & 2.592 & .111 & -.248 & 95 & .805 \\
\hline
\end{tabular}

- There was no significant effect of attachment style, $\mathrm{t}(94)=-1.485, \mathrm{p}=.141$, despite non-secure $(\mathrm{M}=18.23, \mathrm{SD}=4.969)$ showing higher positive qualities than secure $(M=15.34, \quad S D=6.730) \quad$ in friendships.

- There was no significant effect of attachment style, $\mathrm{t}(94)=-.411, \mathrm{p}=.682$, despite non-secure $(\mathrm{M}=10.23, \mathrm{SD}=3.345)$ showing higher negative qualities than secure $(\mathrm{M}=9.64, \quad \mathrm{SD}=5.006) \quad$ in friendships.

- There was significant effect of attachment style, $\mathrm{t}(95)=2.293, \mathrm{p}=.024$, despite secure $(\mathrm{M}=13.57, \quad \mathrm{SD}=6.864)$ showing higher positive qualities than non-secure $(\mathrm{M}=8.92, \quad \mathrm{SD}=6.344) \quad$ in sibling relationships.

- There was no significant effect of attachment style, $\mathrm{t}(95)=-.248, \mathrm{p}=.805$, despite secure $(\mathrm{M}=10.67, \quad \mathrm{SD}=5.304)$ showing higher negative qualities than non-secure $\quad(\mathrm{M}=11.08, \quad \mathrm{SD}=7.041)$ in sibling relationships.

\subsection{DISCUSSION}

Building upon past research we found that attachment style is linked with relationships (Boute, 2009; Fraley and Feris, 2005; Freitag, Belsky, Grossmann, Grossmann, \& ScheuererEnglisch, 1996; Kerns, 1994; Kerns, Klepac, \& Cole, 1996; Lieberman, Doyle, \& Markiewicz, 1999; Park \& Waters, 1989; Schneider, Atkinson, \& Tardif, 2001; Shulman, Elicker, \& Sroufe, 1994; Youngblade, Park, \& Belsky, 1993). Our findings suggest that differences in attachment style do not play a major role in shaping friendships, but significant role in sibling relationships of adolescents. So, our hypothesis 1 and 2 that a significant relationship exists between attachment style with positive and negative features of friendship is not accepted. But for sibling

relationships, positive features are seen to be significant with attachment style, whereas negative features are insignificant. Thus, accepting hypothesis 3 and not accepting hypothesis 4 . The mean scores of positive and negative features of friendship in secure and non-secure individuals suggest that non secure scores high on both. For sibling relationships, positive features are seen high in secure individuals and negative are reported higher in non-secure individuals, as seen in Graph 1.

In reference to relationships of secure and nonsecure individuals in terms of friendships, we may say that our hypothesis of attachment theory between child parent and child sibling and peer relationships is not supported by our study. Attachment theory states that a secure parental tie is necessary for successful development of adolescence, (Bowlby,1969; Blos, 1967; Steinberg and Silverberg,1986) and is also a guiding principle for their relationships (Bretherton and Munholland, 1990). It is clear that our data does not support the hypothesis and proposes an insignificant relationship between the role of attachment style with friendship and sibling relationships. Our findings also suggest that non-secure individuals report higher levels of positive and negative features of relationships with their friends. Douvan and Adelson characterized that the pure influence is increased by the onset of adolescence, they start to spend more time with their friends, although this relationship is curvilinear i.e., it decreases after late adolescence. At this stage, adolescence attempt to separate from the family and peers fill their social and emotional war void left by disengagement from their family. The attachment theory combined with the view of Douvan and Aldeson might be a possible explanation for our findings. Non-secure individuals who are unable to develop an affectionate bond with their primary caregiver tend to engage more in their friendships involving both positive and negative features. Various researches support the relationship between attachment and friendships (Buote at. al, 2009; Fraley and Davis, 2005; Bippus and Rolin, 2009; Mccarthy,2011; Mikulincer M. and Selinger M.,2001; Saferstein et. al.,2005;). Researches also link secure individuals with faster decreases in mental health symptoms as a function of violence relative to their insecurely attached peers as they transitioned into adulthood (Heinze J. et. al.,2018) and may be a useful 
Volume 9 Issue 4 April 2021

construct for examining factors affecting adjustment and treatment response of patients with chronic pain / (Ciechanowski P. et. al.,2003).

Other findings suggest that positive features of sibling relationship were reported higher and secure individuals and negative in non-secure individuals, which supports the proposition by attachment theory. This also supports the proposition that child might imitate a particular interaction style with others based on their interactions with their primary caregivers (Youngblade and Belsky, 1992). It is consistent with the studies done earlier, which indicate that people use their parental ties (Bowlby, 1969), psychological closeness and emotional interdependence while maintaining relationships with siblings (Myers S. and Goodboy A.,2010). Researches also suggest that positive attitude towards siblings affect attachment style and higher romantic relationships (Sommantico $\mathrm{S}$. et. al.,2018). Sibling relationship is influenced by the quality of parent child interactions (Brody et al., 1994; Bussell et al., 1999, Milevsky A. et. al., 2011). Positive features like cohesion and harmony appeared to be linked with more positive sibling relationships (Jodi, Bridges, Kim, Mitchell, \& Chan, 1999).

Nevertheless, it must be remembered that one limitation of this study is that the data sample is low due to which generalization is not possible. Another limitation is the data is collected from the subjects which might be dependent on their mood, emotions and influenced by their relationships with their parents, siblings, peers and their emotional states. New studies might include birth order and gender differences and include other relationships to investigate their influences on each other and other relevant variables. The study will be helpful in understanding attachment styles and relationships of adolescents. It will also help them understand their behaviour and find solutions to various relationship and behavioural problems. The implications of this study will be in counselling as well as school settings to make the counsellors aware of the possible linkages and behaviour of adolescents in their relationships.

\subsection{SUMMARY AND CONCLUSION}

The study focussed on investigating the role of attachment style on friendships and sibling relationships of adolescents. Results indicate that differences in attachment style partly affect the sibling relationships, but not friendships. Attachment style was seen significant with positive features of sibling relationships. Findings also suggest that non secure individuals reported higher levels of friendship. For sibling relationships, positive features were reported higher in secure and negative higher in non-secure individuals.

\section{REFERENCES}

Akhtar, Z. (2012). The effect of parenting style of parents on the attachment styles of undergraduate students. Language in India, 12(1), 555-566.

Bippus, A. M., \& Rollin, E. (2003). Attachment style differences in relational maintenance and conflict behaviours: Friends' perceptions. Communication Reports, 16(2), 113-123.

Buote, V. M., Wood, E., \& Pratt, M. (2009). Exploring similarities and differences between online and offline friendships: The role of attachment style. Computers in Human Behaviour, 25(2), 560-567.

Ciechanowski, P., Sullivan, M., Jensen, M., Románo, J., \& Summers, H. (2003). The relationship of attachment style to depression, catastrophizing and health care utilization in patients with chronic pain. Pain, 104(3), 627-637.

Fraley, \& Davis, (1997). Attachment formation and transfer in young adults 'close friendships and romantic relationships. Personal Relationships, 4(2), 131-144.

GRABILL, \& KERNS,(2000). Attachment style and intimacy in friendship. Personal Relationships, 7(4), 363-378.

Heinze, J. E., Cook, S. H., Wood, E. P., Dumadag, A. C., \& Zimmerman, M. A. (2017). Friendship Attachment Style Moderates the Effect of Adolescent Exposure to Violence on Emerging Adult Depression and Anxiety Trajectories. Journal of Youth and Adolescence, 47(1), 177-193.

Laursen, B., \& Mooney, K. S. (2008). Relationship network quality: Adolescent adjustment and perceptions of relationships with parents and 
Volume 9 Issue 4 April 2021

friends. American Journal of Orthopsychiatry, 78(1), 47-53.

McCarthy, G. (1999). Attachment style and adult love relationships and friendships: A study of a group of women at risk of experiencing relationship difficulties. British Journal of Medical Psychology, 72(3), 305-321.

Mikulincer, M., \& Selinger, M. (2001). The Interplay between Attachment and Affiliation Systems in Adolescents' Same-Sex Friendships: The Role of Attachment Style. Journal of Social and Personal Relationships, 18(1), 81-106.

Myers, S. A., \& Goodboy, A. K. (2013). Using Equity Theory to Explore Adult Siblings' Use of Relational Maintenance Behaviours and Relational Characteristics. Communication Research Reports, 30(4), 275-281.

Oliva, A., \& Arranz, E. (2005b). Sibling relationships during adolescence. European Journal of Developmental Psychology, 2(3), 253270.

Saferstein, J. A., Neimeyer, G. J., \& Hagans, C. L. (2005). Attachment as a predictor of friendship qualities in college youth. Social Behaviour and Personality: An International Journal, 33(8), 767 776.

Shechtman, Z., \& Rybko, J. (2004). Attachment Style and Observed Initial Self-Disclosure as Explanatory Variables of Group Functioning. Group Dynamics: Theory, Research, and Practice, 8(3), 207.

Sommantico, M., Donizzetti, A. R., Parrello, S., \& De Rosa, B. (2018). Predicting Young Adults' Romantic Relationship Quality: Sibling Ties and Adult Attachment Styles. Journal of Family Issues, 40(5), 662-688.

Sommantico, M., Donizzetti, A. R., Parrello, S., \& De Rosa, B. (2018). Predicting Young Adults' Romantic Relationship Quality: Sibling Ties and Adult Attachment Styles. Journal of Family Issues, 40(5), 662-688.
Van Dam, D. S., Korver-Nieberg, N., Velthorst, E., Meijer, C. J., \& de Haan, L. (2014). Childhood maltreatment, adult attachment and psychotic symptomatology: a study in patients, siblings and controls. Social Psychiatry and Psychiatric Epidemiology, 49(11), 1759-1767.

Weimer, B. L., Kerns, K. A., \& M. Oldenburg, C. (2004). Adolescents' interactions with a best friend: Associations with attachment style. Journal of Experimental Child Psychology, 88(1), 102-120.

Youniss, J., \& Haynie, D. L. (1992, March 1). Friendship in Adolescence. ResearchGate. https://www.researchgate.net/publication/21599931 _Friendship_in_Adolescence 